\title{
Comprehensive association analyses of IGF1, ESR2, and CYP17 genes with adult height in Caucasians
}

\author{
Tie-Lin Yang ${ }^{1}$, Dong-Hai Xiong ${ }^{2}$, Yan Guo ${ }^{1}$, Robert R Recker ${ }^{2}$ and Hong-Wen Deng ${ }^{\star}, 1,3,4$
}

${ }^{1}$ The Key Laboratory of Biomedical Information Engineering of Ministry of Education, Institute of Molecular Genetics, School of Life Science and Technology, Xi'an Jiaotong University, Xi'an, PR China; ${ }^{2}$ Department of Biomedical Sciences, Osteoporosis Research Center, Creighton University, Omaha, NE, USA; ${ }^{3}$ Department of Orthopedic Surgery, School of Medicine, University of Missouri-Kansas City, Kansas City, MO, USA; ${ }^{4}$ Department of Basic Medical Science, School of Medicine, University of Missouri-Kansas City, Kansas City, MO, USA

Human adult height is closely related to body growth that is regulated by multiple cytokines or hormones like growth hormone $(\mathrm{GH})$ and estrogen. Our study focused on three potential candidate genes to human height, namely IGF1 (insulin-like growth factor 1), ESR2, and CYP17. We genotyped 43 single nucleotide polymorphisms (SNPs) and tested their associations in 1873 subjects from 405 nuclear families, using both the family-based quantitative transmission disequilibrium test (QTDT) and population-based ANOVA methods. Both analyses consistently detected that two novel SNPs of IGF1, rs5742694 and rs2033178, were significantly associated with human height, with the $P$-values of 0.0097 and 0.0057 in QTDT analyses, $0.0002 / 0.004$ (sample 1/sample 2) and $8.46 \times 10^{-5} / 1.92 \times 10^{-5}$ in ANOVA analyses. For ESR2, significant associations were only detected in women (rs1256061: QTDT $P=0.002$, ANOVA $P=0.002 / 0.012$; rs17766755: QTDT $P=0.019$, ANOVA $P=0.023 / 0.006 ;$ rs1256044: QTDT $P=0.022$, ANOVA $P=0.002 /$ 0.034). Haplotype analyses corroborated our single-SNP results. However, no association was detected between CYP17 and human height. In conclusion, we identified the important effects of IGF1 and ESR2 on adult height variation in Caucasians, and first suggested the potential sex-specific effect of ESR2 on height variation in Caucasian women. It will be valuable for other independent studies to replicate and confirm these findings.

European Journal of Human Genetics (2008) 16, 1380-1387; doi:10.1038/ejhg.2008.113; published online 18 June 2008

Keywords: IGF1; ESR2; CYP17; SNP; association; height

Introduction

Human adult height is a complex trait with high heritability of more than $75 \% .{ }^{1-3}$ Variation in height has been associated

\footnotetext{
${ }^{*}$ Correspondence: Dr H-W Deng, The Key Laboratory of Biomedical Information Engineering of Ministry of Education, Institute of Molecular Genetics, School of Life Science and Technology, Xi'an Jiaotong University, Xi'an 710049, PR China or Department of Orthopedic Surgery, School of Medicine, University of Missouri-Kansas City, 2411 Holmes Street, Room M3-CO3, Kansas City, MO 64108-2792, USA.

Tel: + 1816235 5354; Fax: + 1816235 6517;

E-mail: dengh@umkc.edu

Received 30 October 2007; revised 5 May 2008; accepted 22 May 2008; published online 18 June 2008
}

with risk of some common diseases, such as type 2 diabetes, ${ }^{4}$ osteoporotic fractures, ${ }^{5}$ cardiovascular diseases, ${ }^{6}$ prostate cancer, ${ }^{7}$ as well as disease-specific mortalities in different populations. ${ }^{8}$ It is thus important to investigate human adult height because this may also provide new insights into the mechanisms of other related diseases.

Human adult height is highly correlated with body growth ${ }^{9,10}$ and regulated by multiple genetic factors. Growth hormone $(\mathrm{GH})$ and estrogen are two of the most important hormones regulating body growth. $\mathrm{GH}$ is involved in GH/IGF1 (insulin-like growth factor 1) pathway and exerts systemic and local control on hypothalamus-pituitary-growth plate axis influencing 
longitudinal bone growth. ${ }^{9,11}$ Estrogen endocrine system has been shown to have pleiotropic effects on many endocrine pathways such as cell proliferation and differentiation, and skeletal metabolism. ${ }^{10,12}$ Furthermore, the biosynthesis or metabolisms of these two hormones are regulated by many factors. For instance, IGF1 gene mediates the growth-promoting effects of GH. CYP19 (cytochrome P450 19) and CYP17 genes, encoding the key enzymes, catalyze the in vivo biosynthesis of active estrogens from their lipid precursors. ${ }^{13,14}$ ESR1 and ESR2 encode estrogen receptors $\alpha$ and $\beta$. Therefore, IGF1, CYP17, CYP19, ESR1, and ESR2 genes may have effects on human adult height variation. Previous studies have performed height association studies for some of those genes including IGF1, CYP17, CYP19, and ESR 1, ${ }^{15-21}$ which showed the potential importance of certain genes. ${ }^{15,16,22,23}$ Among them, ESR1 and CYP19 $9^{15,16}$ were identified to associate with height by our studies. In this study, we focused on three genes that are not intensively studied before, namely IGF1, ESR2 and CYP17 genes. Especially, ESR2 has not been investigated by association studies with human adult height so far. Here we characterized the LD (linkage disequilibrium) patterns and haplotype structures of these three genes using high-density single nucleotide polymorphisms (SNPs) and then tested the associations with adult height variation in 1873 Caucasians from 405 nuclear families.

\section{Materials and methods Subjects}

The study was approved by the Creighton University Institutional Review Board. Signed informed consent documents were obtained from all study participants before they entered the study. In brief, all of the 1873 participants from 405 nuclear families were US Caucasians of European origin and recruited randomly in terms of height variation. People with chronic diseases and conditions that might potentially affect height were excluded as detailed before. ${ }^{24}$ All height measurements without shoes were made using a standard wall mounted statiometer in the clinic by nurses. The basic characteristics of the study subjects are presented in Table 1. For the 405 nuclear families used in association analyses, the average family size was $4.63 \pm 1.78$ (mean $\pm \mathrm{SD}$, standard deviation), ranging from 3 to 12 . The overall sample yielded a total of 1512 sib pairs.

\section{Genotyping}

Genomic DNA was extracted from whole blood, using a commercial isolation kit (Gentra Systems, Minneapolis, MN, USA). All SNPs were identified through searching public databases such as HapMap (http://www.hapmap.org/), dbSNP (http://www.ncbi.nlm.nih.gov/SNP/), JSNP (http://snp.ims.u-tokyo.ac.jp/), HGVbase (http://hgv-base. cgb.ki.se/), SNP Consortium (TSC) (http://snp.cshl.org/), and SNPper (http://snpper.chip.org/bio/snpper-enter), based on the following criteria: (1) validation status, especially in Caucasians, (2) an average density of $1 \mathrm{SNP}$ per $4 \mathrm{~kb}$, (3) degree of heterozygosity, that is, minor allele frequencies (MAFs) $>0.05$, (4) functional relevance and importance, (5) tagging SNP information (on the basis of data from HapMap), and (6) reported to dbSNP by various sources. A total of 48 SNPs in or around IGF1, ESR2, and CYP17 genes were successfully genotyped using the high-throughput BeadArray SNP genotyping technology of Illumina Inc. (San Diego, CA, USA) and 43 were analyzed subsequently (5 rare SNPs were abandoned because of insufficient power to analyze them in association studies). The average rate of missing genotype data was reported to be $\sim 0.05 \%$ by Illumina. The average genotyping error rate estimated through blind duplicating was reported to be less than $\sim 0.01 \%$. The information of the 43 analyzed SNPs was summarized in Table 2.

We used PedCheck ${ }^{25}$ to check Mendelian inheritance errors of SNP genotype data and any inconsistent genotypes were removed. Then the error checking option embedded in Merlin ${ }^{26}$ was run to identify and discard the genotypes flanking excessive recombinants, thus further reducing genotyping errors. Less than $0.02 \%$ of total genotypes was removed due to the violation of any of the above two rules. Allele frequencies for each SNP were calculated using the method of Mendel for family data, ${ }^{27}$ and the Hardy-Weinberg equilibriums were tested using the Pedstats procedure in Merlin.

\section{LD and haplotype analyses}

Our LD and haplotype analyses were based on the 703 unrelated parents (340 men and 363 women) from the 405 nuclear families. Population haplotypes and their frequencies were inferred using Phase v2.1.1. ${ }^{28}$ We used HaploBlockFinder $^{29}$ to identify block structures and select haplotype-tagging SNPs (htSNPs). To generate graphical representation of $\mathrm{LD}$ structure as measured by $\left|\mathrm{D}^{\prime}\right|$, we

Table 1 Characteristics of study subjects genotyped in 405 nuclear families

\begin{tabular}{lllll}
\hline Characteristic & \multicolumn{1}{c}{ Sons $(n=385)$} & Daughters $(n=729)$ & Fathers $(n=370)$ & Mothers $(n=370)$ \\
\hline Mean \pm SD (range) & & & & \\
$\quad$ Height $(\mathrm{m})$ & $1.80 \pm 0.07(1.58-1.98)$ & $1.65 \pm 0.06(1.48-1.90)$ & $1.77 \pm 0.07(1.56-1.96)$ & $1.62 \pm 0.06(1.43-1.86)$ \\
Age (years) & $35.7 \pm 11.1(20-74)$ & $37.9 \pm 10.2(20-67)$ & $63.0 \pm 10.7(42-87)$ & $62.5 \pm 10.59(40-86)$ \\
\hline
\end{tabular}

A total of 4 sons and 15 daughters with age $<20$ years were deleted to guarantee the height data collected at recruitment representing the final stature data. 
Table 2 Information of the studied SNPS

\begin{tabular}{|c|c|c|c|c|c|}
\hline SNP no. & $\begin{array}{l}d b S N P \\
\text { rs no. }\end{array}$ & SNP & Frequency $^{\mathrm{a}}$ & $\begin{array}{l}\text { Location } \\
\text { (bp) }\end{array}$ & $\begin{array}{l}\text { SNP } \\
\text { position }\end{array}$ \\
\hline IGF1_1 & rs2373720 & $A / G$ & 0.0602 & 101282429 & $3^{\prime}$ UTR \\
\hline 2 & rs6219 & & 0.0988 & 101292659 & Exon4 \\
\hline 3 & 6214 & $A / G$ & 0.3971 & 101296036 & Exon4 \\
\hline 4 & 5742694 & $\mathrm{C} / \mathrm{A}$ & 0.2457 & 101301703 & Intron3 \\
\hline 5 & 978458 & $A / G$ & 0.2619 & 101304706 & Intron3 \\
\hline 6 & rs4764883 & $\mathrm{G} / \mathrm{A}$ & 0.2834 & 101308772 & Intron3 \\
\hline 7 & \$11111267 & $\mathrm{G} / \mathrm{A}$ & 0.1882 & 101313706 & Intron3 \\
\hline 8 & & $A / G$ & 0.1882 & & Intron2 \\
\hline 9 & & & & & Intron2 \\
\hline 10 & & $\mathrm{G} / \mathrm{C}$ & 0.24 & 101329512 & Intron2 \\
\hline 11 & 2288378 & $A / G$ & 0.2461 & 101332475 & Intron2 \\
\hline 12 & rs10735380 & $\mathrm{G} / \mathrm{A}$ & 0.2749 & 101346703 & Intron2 \\
\hline 13 & & $A / G$ & & & Intron2 \\
\hline 14 & & & & & \\
\hline 15 & & $\mathrm{G} / \mathrm{A}$ & & & Intron2 \\
\hline 16 & 1019 & $A / C$ & 0.1 & 66892 & Intron2 \\
\hline 17 & & $A / G$ & & & Intron2 \\
\hline 18 & & $\mathrm{G} / \mathrm{A}$ & & & Intron1 \\
\hline 19 & & $\mathrm{~A} / \mathrm{C}$ & & & $5^{\prime}$ UTR \\
\hline ESR2_1 & & $\mathrm{G} / \mathrm{A}$ & & & \\
\hline 2 & & $A / C$ & & & JTR \\
\hline 3 & & $\mathrm{~A} / \mathrm{G}$ & & & JTR \\
\hline 4 & & $\mathrm{~A} / \mathrm{C}$ & & & ron7 \\
\hline 5 & & $A / G$ & & & Intron7 \\
\hline 6 & 17766755 & $A / G$ & & & Intron7 \\
\hline 7 & & $\mathrm{G} / \mathrm{A}$ & & & Intron6 \\
\hline 8 & & $\mathrm{~A} / \mathrm{G}$ & & & \\
\hline 9 & & $\mathrm{G} / \mathrm{A}$ & & & Intron4 \\
\hline 10 & & $\mathrm{C} / \mathrm{G}$ & & & Intron4 \\
\hline 11 & 10148269 & $A / G$ & & & Intron3 \\
\hline 12 & & $\mathrm{G} / \mathrm{A}$ & & & Intron3 \\
\hline 13 & & $A / G$ & & & Intron2 \\
\hline 14 & & $\mathrm{~A} / \mathrm{C}$ & & 25 & Intron1 \\
\hline 15 & rs17179740 & $A / G$ & 0.35 & & Intron1 \\
\hline 16 & & $A / C$ & & & $5^{\prime}$ UTR \\
\hline 17 & rs3020450 & $\mathrm{A} / \mathrm{G}$ & 0.3134 & 63838055 & $5^{\prime}$ UTR \\
\hline YP17_1 & & & & & \\
\hline 2 & & $\mathrm{~A} / \mathrm{G}$ & & & $3^{\prime}$ UTR \\
\hline 3 & rs4919685 & $A / C$ & 0.2967 & 104577352 & $3^{\prime}$ UTR \\
\hline 4 & & $\mathrm{~A} / \mathrm{T}$ & & & Intron7 \\
\hline 5 & & $\mathrm{G} / \mathrm{C}$ & & & Intron5 \\
\hline 6 & & $\mathrm{~A} / \mathrm{C}$ & & & Exon1 \\
\hline 7 & rs11191416 & $\mathrm{C} / \mathrm{A}$ & 0.0894 & 104594906 & Promot \\
\hline
\end{tabular}

${ }^{a}$ Allele frequencies for the first allele (minor allele) are shown.

adopted Haploview ${ }^{30}$ to yield similar haplotype block structures when compared to HaploBlockFinder. To infer haplotypes defined by the htSNPs within each block, we adopted the algorithm of integer linear programming (ILP) implemented in PedPhase V2.0, ${ }^{31}$ which is based on LD assumption and able to recover phase information at each marker locus with great speed and accuracy even in the presence of $20 \%$ missing data.

\section{Statistical analysis of association}

In association analyses, significant covariates including age and sex were used to adjust for the height data in the total sample. In sex-specific analyses, age was used as covariate. Normality tests and adjustments were done by MINITAB. The quantitative transmission disequilibrium test (QTDT) $^{32}$ was used to test the htSNPs and haplotypes with estimated frequencies greater than $5 \%$ for associations with height. We adopted the orthogonal model implemented in QTDT for our analyses, which incorporates the variance components method in the analysis of family data and includes exact estimation of $P$-values. Monte-Carlo permutation test ${ }^{33}$ were performed 10000 times to correct for multiple testing of markers and genes tested. The significant threshold was established as 0.0033 for an individual test to achieve a global significance level of 0.05 for our analyses.

Then we performed population-based association analyses by ANOVA for both single-SNP and haplotypes (frequencies greater than 5\%) versus height in Minitab software (Minitab Inc., State College, PA, USA). ANOVA tests were repeated in two unrelated samples to validate the results. As we have no additional sample, we extracted the unrelated subjects from the entire sample. For 'Total' sample, we selected the parental generation as sample 1 (630 subjects), and then randomly selected one child from each family as sample 2 (400 subjects). For 'female' subjects, one daughter from each family was randomly selected to generate sample 1 (326 subjects), then one daughter from the rest members of each family was randomly selected as sample 2 (312 subjects). For 'male' sample, as our sample contained more female subjects than male subjects, and many families had no son or only one son, we randomly selected one son from each family (210 subjects) as sample 1 , and then fathers (300 subjects) were selected as sample 2 .

\section{Bioinformatic analysis}

We used Vista program (http://www-gsd.lbl.gov/VISTA/ index.shtml) to compare the interesting genomic sequences from human and mouse, which visualize the pairwise percentage identity as calculated for every $100 \mathrm{bp}$. Potential SNP functions like transcriptional factor binding sites (TFBSs) were queried by using a web-based Bioinformatics tool named FASTSNP (function analysis and selection tool for SNPs, http://fastsnp.ibms.sinica.edu.tw). ${ }^{34}$

\section{Results}

LD and haplotype analyses

Figure 1 shows the LD structures of these three genes. For IGF1 gene, 7 htSNPs (SNP 2, 3, 4, 13, 16, 17, and 19) were selected to represent three blocks containing 18 SNPs with the size of 13,53 , and $17 \mathrm{~kb}$, separately. SNP 15 could not be assigned to any block due to its low LD with the SNPs around. The average density of these 19 SNPs was $4.5 \mathrm{~kb} /$ SNP. For ESR2 gene, two blocks with high LD were identified, which contained 17 SNPs with an average 
IGF1
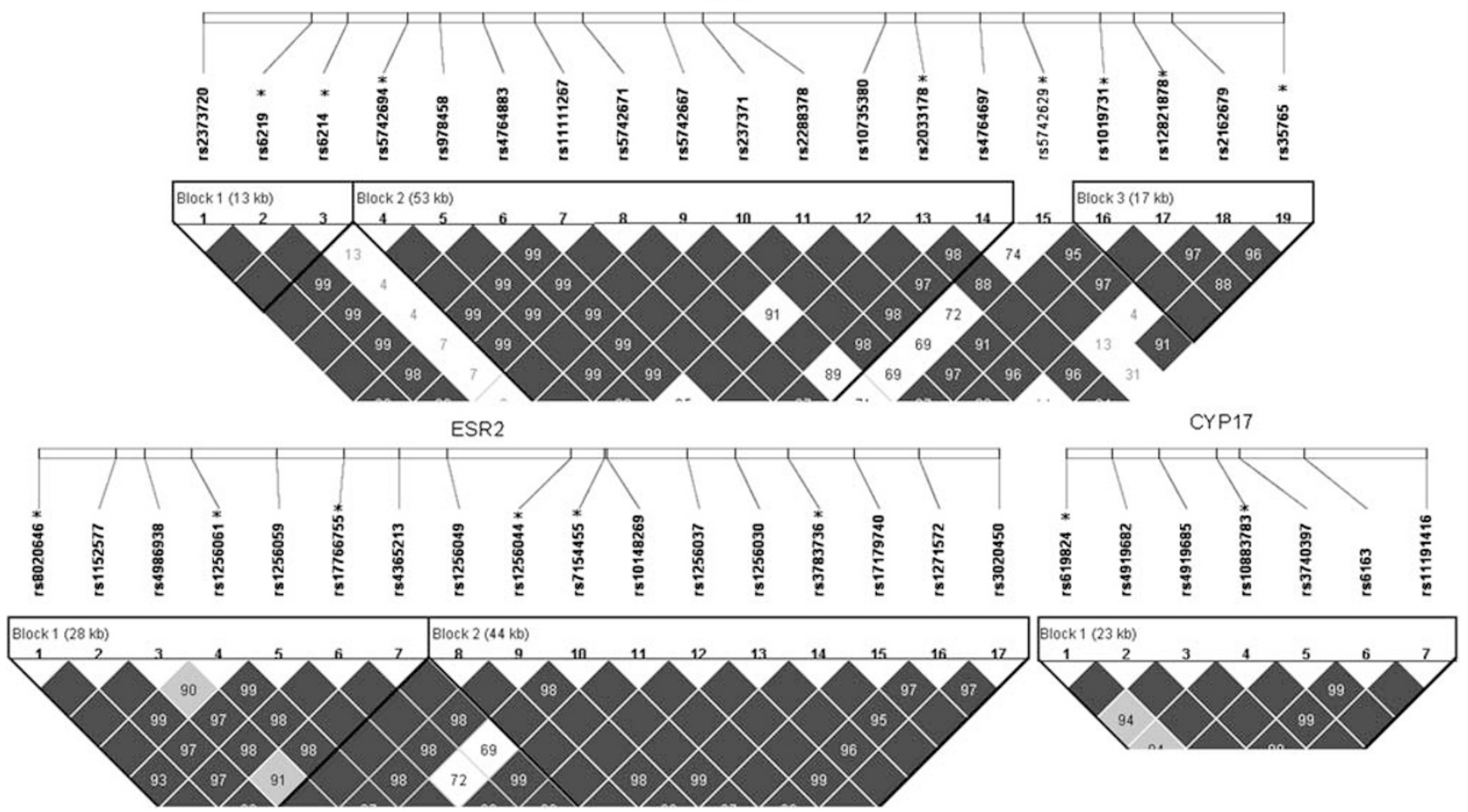

Figure 1 The linkage disequilibrium (LD) structures of IGF1, ESR2, and CYP17 genes. Squares in black indicate strong LD; *, tag SNPs; numbers in bracket, the length of blocks. For IGF1, SNP 15 had weak LD with some SNPs in Block 2 or Block 3, so it cannot be assigned to any of the blocks.

Table 3 Single-SNP analysis for human adult height

\begin{tabular}{|c|c|c|c|c|c|c|c|c|c|}
\hline \multirow[b]{2}{*}{$S N P^{a}$} & \multicolumn{3}{|c|}{$\begin{array}{c}\text { P-value in 'total' sample } \\
\text { ANOVA }\end{array}$} & \multicolumn{3}{|c|}{$\begin{array}{c}\text { P-value in 'female' sample } \\
\text { ANOVA }\end{array}$} & \multicolumn{3}{|c|}{$\begin{array}{c}\text { P-value in 'male' sample } \\
\text { ANOVA }\end{array}$} \\
\hline & QTDT & $S 1(630) / S 2(400)$ & $r^{2}(\%)^{c}$ & QTDT & S1 (326)/S2 (312) & $r^{2}(\%)$ & QTDT & S1 (210)/S2 (300) & $r^{2}(\%)$ \\
\hline 2 & 0.968 & $0.512 / 0.850$ & 0.00 & 0.219 & $0.474 / 0.725$ & 0.00 & 0.173 & $0.795 / 0.710$ & 0.00 \\
\hline 3 & 0.952 & $0.021 / 0.429$ & 1.29 & 0.872 & $0.085 / 0.519$ & 0.95 & 0.179 & $0.019 / 0.829$ & 2.33 \\
\hline 4 & 0.0097 & $0.0002 / 0.004$ & 2.05 & 0.034 & $2.38 \times 10^{-4} / 4.29 \times 10^{-5}$ & 5.23 & 0.081 & $0.004 / 0.003$ & 3.75 \\
\hline 13 & 0.0057 & $8.46 \times 10^{-5} / 1.92 \times 10^{-5}$ & 2.19 & 0.0015 & $2.11 \times 10^{-5} / 1.10 \times 10^{-4}$ & 6.00 & 0.149 & $0.003 / 0.001$ & 3.83 \\
\hline 17 & 0.228 & $0.808 / 0.361$ & 0.00 & 0.032 & $0.014 / 0.25$ & 2.00 & 0.509 & $0.872 / 0.339$ & 0.00 \\
\hline 19 & 0.926 & $0.035 / 0.014$ & 1.12 & 0.249 & $0.013 / 0.003$ & 2.04 & 0.649 & $0.872 / 0.287$ & 0.00 \\
\hline \multicolumn{10}{|l|}{ ESR2 } \\
\hline 1 & 0.502 & $0.168 / 0.129$ & 0.61 & 0.380 & $0.181 / 0.112$ & 0.55 & 0.777 & $0.928 / 0.307$ & 0.00 \\
\hline 4 & 0.061 & $0.012 / 0.009$ & 1.50 & 0.002 & $0.002 / 0.012$ & 3.19 & 0.588 & $0.634 / 0.119$ & 0.00 \\
\hline
\end{tabular}

Abbreviations: IGF1, insulin-like growth factor 1; QTDT, quantitative transmission disequilibrium test; SNP, single nucleotide polymorphism. ${ }^{a}$ SNPs listed here are htSNPs.

${ }^{\mathrm{b}} P$-values $<0.05$ are shown in bold italics. S1, sample 1; S2, sample 2. Numbers in bracket are sample size.

${ }^{c} r^{2}$ indicates how much variation in the AAM is explained by the SNP, which is measured by the ANOVA in S1.

density of $1 \mathrm{SNP}$ per $4.2 \mathrm{~kb}$. For each block, three htSNPs (block 1: SNP 1, 4, and 6; block 2: SNP 9, 10, and 14) were inferred to represent common haplotypes. Only one block
(htSNPs:SNP 1 and 4) was identified for CYP17 gene with the size of $23 \mathrm{~kb}$, containing seven SNPs. The average density is $1 \mathrm{SNP}$ per $3.3 \mathrm{~kb}$. 


\section{Association analyses}

All of the association results are presented in Table 3 (single-SNP analyses) and Table 4 (haplotype analyses). For IGF1 gene, SNP 4 and 13 were detected as significant to human adult height by QTDT test in total sample with $P$-values of 0.0097 and 0.0057 , respectively. They were still significant in female sample (SNP 4: $P=0.034$; SNP 13: $P=0.0015)$. However, only marginally significant result was found in SNP 4 in male sample $(P=0.081)$. The results of these two SNPs in ANOVA analyses of both samples 1 and 2 showed consistent and more significant results (Table 3). The contribution of SNP $4 / 13$ to the variation of height was 5.23/6.00 and 3.75/3.83\% in female and male samples, respectively. Interestingly, SNP 4 and 13 were only two htSNPs in block 2, and the results of haplotype analyses were consistently significant in ANOVA in all three categories sample (total, female, and male samples), but not in QTDT (Table 4). For ESR2 gene in total sample, SNP 4 and 6 were detected as marginally significant to height variation ( $P=0.061$ and 0.066 , separately) by QTDT. When sex-specific analyses were conducted, the significant association with height was only present in women both in QTDT and ANOVA (Table 3). For haplotype analyses of ESR2 gene in female sample, only block 2-hap8 was nominally significant $(P<0.05)$ in QTDT, which obtained the most significant result in ANOVA analyses $\left(3.6 \times 10^{-4}\right.$ / 0.006 in sample $1 / 2$ ). In addition, block 1-hap4 and block 2-hap1 were detected as nominally significant (Table 4 ). No significant result was found by either single-SNP or haplotype analyses in CYP17 gene using the two statistical methods adopted here (data not shown).

\section{Bioinformatic analysis}

Vista program was used to compare the genomic sequences of IGF1 and ESR2 genes from human and mouse. SNP 5, 6, $7,11,13$, and 14 in block 2 of IGF1 gene and SNP 8 of ESR2 gene were all located in noncoding conserved regions, the detailed results are shown in Figure 2. In addition, according to the FASTSNP program, two SNPs of ESR2 (rs1256061 and rs7154455) were potentially transcription factor binding sites.

\section{Discussion}

IGF1, ESR2 and CYP17 may have potential effects on human adult height variation, by GH/IGF1 pathway and estrogen endocrine system regulating body growth. Thus, we performed association analyses to investigate whether the common variants in these important candidate genes contribute to the variation of adult height in human. Our work showed that about $12.5 \%$ genetic variation can be explained by the $16 \mathrm{htSNPs}$ in the three genes analyzed here.

IGF1 gene encodes somatomedin $\mathrm{C}$ that is important in mediating the effects of GH. Although several polymorphisms of it have been assessed in the association studies of human

Table 4 Haplotype analysis for human adult height

\begin{tabular}{|c|c|c|c|c|c|c|c|}
\hline \multirow[b]{3}{*}{ Block } & \multirow[b]{3}{*}{ Haplotype } & \multicolumn{2}{|c|}{ P-value in 'total' sample } & \multicolumn{2}{|c|}{ P-value in 'female' sample } & \multicolumn{2}{|c|}{ P-value in 'male' sample } \\
\hline & & & ANOVA & & ANOVA & & ANOVA \\
\hline & & QTDT & $S 1(630) / S 2(400)$ & QTDT & S1 (326)/S2 (312) & QTDT & S1 (210)/S2 (300) \\
\hline Block 1-hap2 & AG & 0.499 & $0.143 / 0.038$ & 0.451 & $0.726 / 0.727$ & 0.106 & $0.770 / 0.906$ \\
\hline Block 1-hap3 & GA & 0.817 & $0.930 / 0.016$ & 0.545 & $0.117 / 0.514$ & 0.148 & $0.050 / 0.563$ \\
\hline Block 1-hap4 & GG & 0.985 & $0.316 / 0.287$ & 0.241 & $0.153 / 0.463$ & 0.642 & $0.860 / 0.863$ \\
\hline Block 2-hap2 & AG & 0.096 & $0.001 / 0.038$ & 0.493 & $2.60 \times 10^{-4} / 0.041$ & 0.035 & $0.002 / 0.010$ \\
\hline Block 2-SNP 15 & - & 0.418 & $0.808 / 0.349$ & 0.379 & $0.784 / 0.806$ & 0.932 & $0.358 / 0.736$ \\
\hline Block 3-hap2 & AAC & 0.505 & $0.256 / 0.413$ & 0.776 & $0.854 / 0.910$ & 0.091 & $0.635 / 0.476$ \\
\hline Block 3-hap6 & CAC & 0.645 & $0.469 / 0.739$ & 0.298 & $0.044 / 0.432$ & 0.867 & $0.667 / 0.138$ \\
\hline Block 3-hap7 & CGA & 0.437 & $0.021 / 0.006$ & 0.278 & $0.024 / 0.268$ & 0.622 & $0.902 / 0.204$ \\
\hline Block 3-hap8 & CGC & 0.788 & $0.545 / 0.150$ & 0.275 & $0.546 / 0.747$ & 0.437 & $0.831 / 0.626$ \\
\hline \multicolumn{8}{|l|}{ ESR2 } \\
\hline Block 2-hap3 & AGA & 0.926 & $0.850 / 0.120$ & 0.452 & $0.391 / 0.945$ & 0.295 & $0.109 / 0.492$ \\
\hline Block 2-hap4 & AGC & 0.032 & $0.664 / 0.398$ & 0.687 & $0.578 / 0.290$ & 0.036 & $0.380 / 0.123$ \\
\hline Block 2-hap8 & $\mathrm{GCC}$ & 0.563 & $0.039 / 0.064$ & 0.048 & $3.6 \times 10^{-4} / 0.006$ & 0.364 & $0.187 / 0.845$ \\
\hline
\end{tabular}

Abbreviations: IGF1, insulin-like growth factor 1; QTDT, quantitative transmission disequilibrium test; SNP, single nucleotide polymorphism. $P$-values $<0.05$ are shown in bold italics. SNP 15 had weak LD with other SNPs and cannot be assigned to any of the blocks. S1, sample 1 ; S2, sample 2. Number in bracket is sample size. 


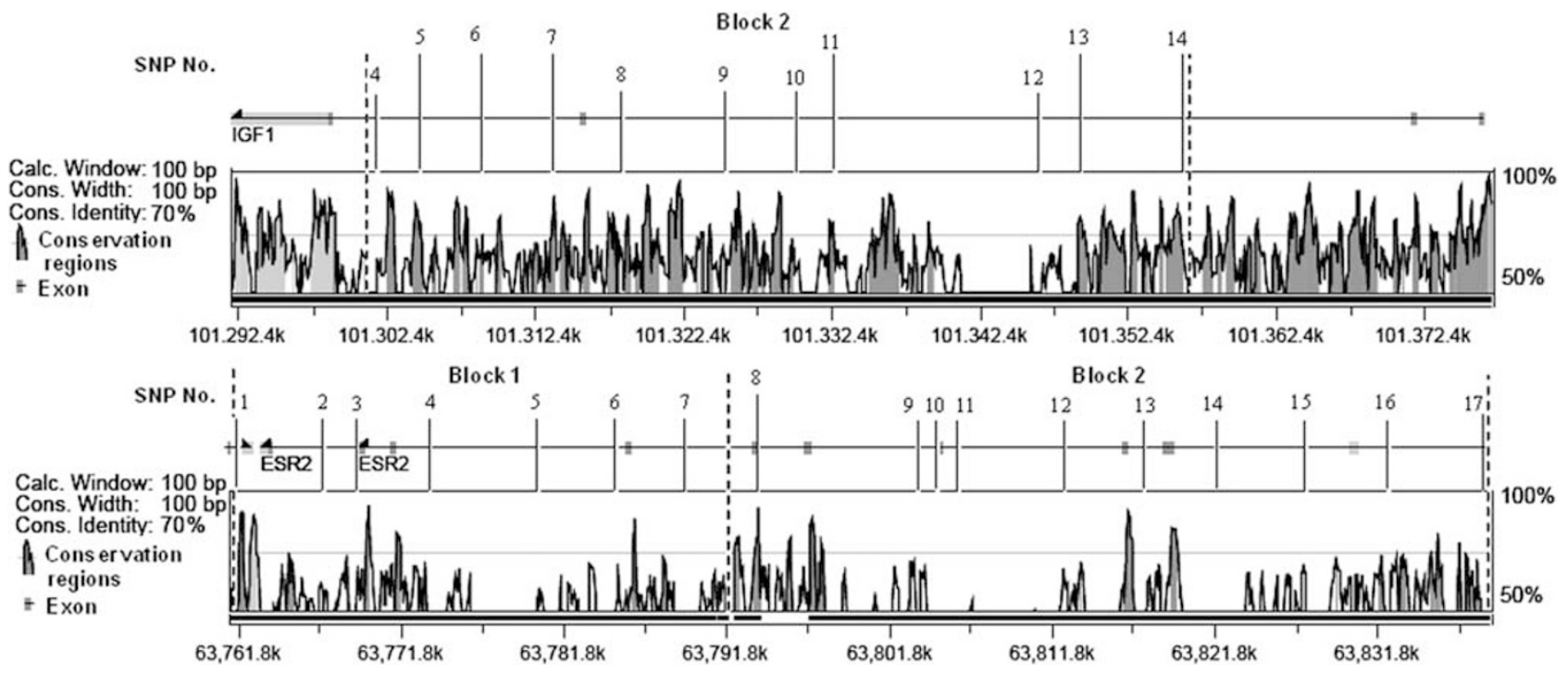

Figure 2 Conservation of the human and mouse genomic IGF1 and ESR2 gene sequence. The region between the two dashed vertical lines represents the region in one block. The longer black bars on the gene symbol indicated the SNPs we selected in conserved regions. The shorter bars indicated the SNPs we selected in non-conserved regions.

adult height, the results were not consistent. ${ }^{17,35}$ Voorhoeve et $a^{21}$ found that there was no statistical significant between wild-type carriers of IGF1 and final height. Frayling et al $^{35}$ reported that a common allele $(Z)$, a microsatellite polymorphism $1 \mathrm{~kb}$ upstream to the IGF1 gene, had no association with adult height. Whereas Rietveld et $a l^{17}$ found a polymorphic CA repeat in IGF1 gene was associated with adult height. In our sample, subjects carrying ' $\mathrm{C}$ ' allele of SNP 4 and 'A' allele of SNP 13 were taller than those carrying ' $A$ ' allele of SNP 4 and ' $G$ ' allele of SNP 13, separately. Notably, the bioinformatics analyses showed that most $I G F 1$ region in block 2 were highly conserved between the human and mouse species. Interestingly, this region may have biological effects on other traits. $^{36-38}$ For example, Johansson et al ${ }^{38}$ reported that this region was associated with prostate cancer risk. Cheng et $a l^{36}$ revealed that some SNPs (ie rs5742637, rs5742639, rs5742657, and rs2072592) belonging to block 2 of this study were associated with prostate cancer risk. In addition, rs1520220 near the SNP4 in this study was detected to be associated with increased circulating IGF1 level and increased risk of breast cancer. ${ }^{37}$ For ESR2, although most SNPs we selected were not conserved compared to mouse species, two significant SNPs (rs1256061 and rs7154455) were in the core recognition sequences of potential TFBS and hence may have a role in transcription regulation.

We, for the first time, performed the association study of ESR2 gene on human adult height based on its biological role as an estrogen receptor. Our results showed that ESR2 gene had sex-specific effects on height, as the association was detected only in women. This can be explained from two aspects. First, the association tests for height in men were statistically less powerful than in women because the size of the male sample $(n=749)$ was much smaller than female sample $(n=1124)$. Second, biological differences exist in terms of height growth between men and women. For instance, the physiology of pubertal growth in females is different from that in men as the former begins and ends earlier and has a lower peak velocity. And adult height in women could be more influenced by in vivo estrogens status due to menarche. ${ }^{39}$

In present study, we used both family-based and population-based methods, which have their own limitations and merits, but can complement each other. Familybased analyses assessed the association through allele transmissions from parent to children, and is robust against population stratification. ${ }^{40}$ In contrast, population-based test may supply higher power than family-based methods to detect association. However, it may increase the false-positive rate. ${ }^{41}$ Therefore, the optimal solution is to use both methods in such context. We estimated the power of our study sample by the Program Genetic Power Calculator (http://pngu.mgh.harvard.edu/ purcell/gpc/ qtlassoc.html) with a conservative significance level of $\alpha=0.001$. Assuming that incomplete LD of $\left|D^{\prime}\right|=0.9$, our sample can reach 90 and $80 \%$ power in men and women, respectively, under additive models to detect a QTL responsible for about $4 \%$ variation of height.

Although the sample we used came from a study of osteoporosis, the subjects were recruited randomly, and we only excluded the subjects with bone-related diseases or other diseases influencing bone development. The exclusion criteria are consistent with analysis for height, as 
abnormal stature is a basic characteristic of many bone disorders. Thus, it is reasonable that we can ignore the sample effect on the analysis of height. Another potential limitation in this study is that some of our adult height data may not represent maximal adult height due to the early loss of height caused by osteopenia, vertebral fractures, loss of intervertebral disc's turgor and elasticity, and kyphosis. Adjusting height by age may only partly overcome the differences between adult heights of younger and older members of the families. However, due to the lack of data in those aspects to adjust the effects of environments, this study represents the best we can do under present conditions.

In summary, we identified the significant effects of two important genes, IGF1 and ESR2, on adult height variation in Caucasians, and first suggested the potential sex-specific effect of ESR2 on women height. However, multiple replication studies are needed to confirm our results and identify the most possible functional variants for molecular studies.

\section{Acknowledgements}

This study was partially supported by grants from NIH (RO1 AR050496, K01 AR02170-01, R01 AR45349-01, and R01 GM60402-01A1) and an LB595 grant from the State of Nebraska. The study also benefited from grants of Project 30570875 supported by National Natural Science Foundation of China, Xi'an Jiaotong University, and the Ministry of Education of China.

\section{Disclosure/Conflict of interest}

The authors declare that they have no competing financial interests.

\section{References}

1 Phillips K, Matheny Jr AP: Quantitative genetic analysis of longitudinal trends in height: preliminary results from the Louisville Twin Study. Acta Genet Med Gemellol (Roma) 1990; 39: $143-163$.

2 Carmichael CM, McGue M: A cross-sectional examination of height, weight, and body mass index in adult twins. J Gerontol A Biol Sci Med Sci 1995; 50: B237-B244.

3 Stunkard AJ, Foch TT, Hrubec Z: A twin study of human obesity. JAMA 1986; 256: 51-54.

4 Lawlor DA, Ebrahim S, Davey SG: The association between components of adult height and Type II diabetes and insulin resistance: British Women's Heart and Health Study. Diabetologia 2002; 45: 1097-1106.

5 Hemenway D, Feskanich D, Colditz GA: Body height and hip fracture: a cohort study of 90000 women. Int J Epidemiol 1995; 24: $783-786$.

6 Forsen T, Eriksson J, Qiao Q et al: Short stature and coronary heart disease: a 35-year follow-up of the Finnish cohorts of The Seven Countries Study. J Intern Med 2000; 248: 326-332.

7 Albanes D, Jones DY, Schatzkin A et al: Adult stature and risk of cancer. Cancer Res 1988; 48: 1658-1662.

8 Jousilahti P, Tuomilehto J, Vartiainen E et al: Relation of adult height to cause-specific and total mortality: a prospective follow-up study of 31199 middle-aged men and women in Finland. Am J Epidemiol 2000; 151: 1112-1120.

9 Green H, Morikawa M, Nixon T: A dual effector theory of growthhormone action. Differentiation 1985; 29: 195-198.

10 Smith EP, Boyd J, Frank GR et al: Estrogen resistance caused by a mutation in the estrogen-receptor gene in a man. $N$ Engl J Med 1994; 331: 1056-1061.

11 Daughaday WH, Hall K, Raben MS et al: Somatomedin: proposed designation for sulphation factor. Nature 1972; 235: 107.

12 Uitterlinden AG, Fang Y, Van Meurs JB et al: Genetics and biology of vitamin D receptor polymorphisms. Gene 2004; 338: 143-156.

13 Mitrunen K, Hirvonen A: Molecular epidemiology of sporadic breast cancer. The role of polymorphic genes involved in oestrogen biosynthesis and metabolism. Mutat Res 2003; 544: $9-41$.

14 Thompson PA, Ambrosone C: Molecular epidemiology of genetic polymorphisms in estrogen metabolizing enzymes in human breast cancer. J Natl Cancer Inst Monogr 2000; 27: 125-134.

15 Lei SF, Deng FY, Xiao SM et al: Association and haplotype analyses of the COL1A2 and ER-alpha gene polymorphisms with bone size and height in Chinese. Bone 2005; 36: 533-541.

16 Yang TL, Xiong DH, Guo Y et al: Association analyses of CYP19 gene polymorphisms with height variation in a large sample of Caucasian nuclear families. Hum Genet 2006; 120: 119-125.

17 Rietveld I, Janssen JA, van Rossum EF et al: A polymorphic CA repeat in the IGF-I gene is associated with gender-specific differences in body height, but has no effect on the secular trend in body height. Clin Endocrinol (Oxf) 2004; 61: 195-203.

18 Zmuda JM, Cauley JA, Kuller LH et al: A common promotor variant in the cytochrome P450c17alpha (CYP17) gene is associated with bioavailability testosterone levels and bone size in men. J Bone Miner Res 2001; 16: 911-917.

19 Ellis JA, Stebbing M, Harrap SB: Significant population variation in adult male height associated with the $\mathrm{Y}$ chromosome and the aromatase gene. J Clin Endocrinol Metab 2001; 86: 4147-4150.

20 Schuit SC, van Meurs JB, Bergink AP et al: Height in pre- and postmenopausal women is influenced by estrogen receptor alpha gene polymorphisms. J Clin Endocrinol Metab 2004; 89: 303-309.

21 Voorhoeve PG, van Rossum EF, Te Velde SJ et al: Association between an IGF-I gene polymorphism and body fatness: differences between generations. Eur J Endocrinol 2006; 154: 379-388.

22 Xiong DH, Xu FH, Liu PY et al: Vitamin D receptor gene polymorphisms are linked to and associated with adult height. J Med Genet 2005; 42: 228-234.

23 Zhang YY, Liu PY, Lu Y et al: Tests of linkage and association of $\mathrm{PTH} / \mathrm{PTHrP}$ receptor type 1 gene with bone mineral density and height in Caucasians. J Bone Miner Metab 2006; 24: 36-41.

24 Xiong DH, Liu YZ, Liu PY et al: Association analysis of estrogen receptor alpha gene polymorphisms with cross-sectional geometry of the femoral neck in Caucasian nuclear families. Osteoporos Int 2005; 16: 2113-2122.

25 O'Connell JR, Weeks DE: PedCheck: a program for identification of genotype incompatibilities in linkage analysis. Am J Hum Genet 1998; 63: 259-266.

26 Abecasis GR, Cherny SS, Cookson WO et al: Merlin - rapid analysis of dense genetic maps using sparse gene flow trees. Nat Genet 2002; 30: 97-101.

27 Boehnke M: Allele frequency estimation from data on relatives. Am J Hum Genet 1991; 48: 22-25.

28 Stephens M, Scheet P: Accounting for decay of linkage disequilibrium in haplotype inference and missing-data imputation. Am J Hum Genet 2005; 76: 449-462.

29 Zhang K, Jin L: HaploBlockFinder: haplotype block analyses. Bioinformatics 2003; 19: 1300-1301.

30 Barrett JC, Fry B, Maller J et al: Haploview: analysis and visualization of LD and haplotype maps. Bioinformatics 2005; 21: $263-265$.

$31 \mathrm{Li} \mathrm{J}$, Jiang T: Computing the minimum recombinant haplotype configuration from incomplete genotype data on a pedigree by integer linear programming. J Comput Biol 2005; 12: 719-739. 
32 Abecasis GR, Cardon LR, Cookson WO: A general test of association for quantitative traits in nuclear families. Am J Hum Genet 2000; 66: 279-292.

33 McIntyre LM, Martin ER, Simonsen KL et al: Circumventing multiple testing: a multilocus Monte Carlo approach to testing for association. Genet Epidemiol 2000; 19: $18-29$.

34 Yuan HY, Chiou JJ, Tseng WH et al: FASTSNP: an always up-to-date and extendable service for SNP function analysis and prioritization. Nucleic Acids Res 2006; 34: W635-W641.

35 Frayling TM, Hattersley AT, McCarthy A et al: A putative functional polymorphism in the IGF-I gene: association studies with type 2 diabetes, adult height, glucose tolerance, and fetal growth in UK populations. Diabetes 2002; 51: $2313-2316$.
36 Cheng I, Stram DO, Penney KL et al: Common genetic variation in IGF1 and prostate cancer risk in the Multiethnic Cohort. J Natl Cancer Inst 2006; 98: 123-134.

37 Al Zahrani A, Sandhu MS, Luben RN et al: IGF1 and IGFBP3 tagging polymorphisms are associated with circulating levels of IGF1, IGFBP3 and risk of breast cancer. Hum Mol Genet 2006; 15: 1-10.

38 Johansson M, McKay JD, Stattin P et al: Comprehensive evaluation of genetic variation in the IGF1 gene and risk of prostate cancer. Int J Cancer 2007; 120: 539-542.

39 Stoll BA: Western diet, early puberty, and breast cancer risk. Breast Cancer Res Treat 1998; 49: 187-193.

40 Spielman RS, Ewens WJ: The TDT and other family-based tests for linkage disequilibrium and association. Am J Hum Genet 1996; 59: 983-989.

41 Schork NJ, Fallin D, Thiel B et al: The future of genetic casecontrol studies. Adv Genet 2001; 42: 191-212. 